\title{
Disruptive Models in Primary Care: Caring for High-Needs, High-Cost Populations
}

\author{
Michael Hochman, MD, MPH and Steven M. Asch, MD, MPH', \\ ${ }^{1}$ The Gehr Family Center for Implementation Science, Keck School of Medicine, University of Southern California, Los Angeles, CA, USA; ${ }^{2}$ Stanford \\ University School of Medicine, Stanford, CA, USA; ${ }^{3}$ The VA Palo Alto Health Care System, Menlo Park, CA, USA.
}

\begin{abstract}
Starfield and colleagues have suggested four overarching attributes of good primary care: "first-contact access for each need; long-term person- (not disease) focused care; comprehensive care for most health needs; and coordinated care when it must be sought elsewhere." As this series on reinventing primary care highlights, there is a compelling need for new care delivery models that would advance these objectives. This need is particularly urgent for highneeds, high-cost (HNHC) populations. By definition, HNHC patients require extensive attention and consume a disproportionate share of resources, and as a result they strain traditional office-based primary care practices. In this essay, we offer a clinical vignette highlighting the challenges of caring for HNHC populations. We then describe two categories of primary care-based approaches for managing HNHC populations: complex case management, and specialized clinics focused on HNHC patients. Although complex case management programs can be incorporated into or superimposed on the traditional primary care system, such efforts often fail to engage primary care clinicians and HNHC patients, and proven benefits have been modest to date. In contrast, specialized clinics for HNHC populations are more disruptive, as care for HNHC patients must be transferred to a multidisciplinary team that can offer enhanced care coordination and other support. Such specialized clinics may produce more substantial benefits, though rigorous evaluation of these programs is needed. We conclude by suggesting policy reforms to improve care for HNHC populations.
\end{abstract}

J Gen Intern Med 32(4):392-7

DOI: $10.1007 / \mathrm{s} 11606-016-3945-2$

(c) The Author(s) 2016. This article is published with open access at Springerlink.com

\section{INTRODUCTION}

Starfield and colleagues ${ }^{1}$ have suggested four overarching attributes of good primary care: "first-contact access for each need; long-term person- (not disease) focused care; comprehensive care for most health needs; and coordinated care when it must be sought elsewhere." As this JGIM symposium on reinventing primary care highlights, there is a compelling need to develop new models for advancing these objectives. The innovations described in this series

Received August 15, 2016

Revised October 25, 2016

Accepted November 22, 2016

Published online February 27, 2017 of articles, particularly models of care delivery within retail clinics and the home environment, ${ }^{2}$ the integration of behavioral health within primary care, ${ }^{3}$ and technological advances facilitating primary care delivery, ${ }^{4}$ could help primary care clinicians work towards Starfield's vision.

The need to deliver on Starfield's aims is particularly urgent for the most vulnerable populations: high-needs patients with complex medical, behavioral health, and social problems, who frequently "fall through the cracks" within the existing healthcare landscape. 5 Such patients commonly report high levels of frustration with the care delivery system, and may experience avoidable complications resulting from disjointed, inaccessible, and poorly aligned care. ${ }^{6}$

Because "high-needs" patients require extensive attention and services, they also consume a disproportionate share of resources. ${ }^{7}$ In many populations, approximately $80 \%$ percent of medical expenditures are concentrated within $20 \%$ of patients and $50 \%$ of costs within $5 \% .{ }^{8}$ As a result, the term "high-needs, high-cost" (HNHC) has emerged to describe these patients. ${ }^{9,10}$ Sophisticated algorithms incorporating comorbidities, ${ }^{11}$ socioeconomic factors, behavioral health and substance abuse diagnoses, geographic factors, and qualitative feedback from providers and staff have been developed for identifying HNHC patients (see Fig. 1). ${ }^{12}$

While improving care for HNHC patients represents an important opportunity, ${ }^{6}$ it also presents a formidable challenge, particularly for traditional office-based primary care practices that lack the multidisciplinary resources these patients so often need. ${ }^{13}$ Primary care clinicians in such clinics often feel ill-equipped to manage HNHC patients, ${ }^{14}$ and may abdicate their role in overseeing their care. Indeed, much of the care for HNHC populations occurs in specialty offices, emergency rooms, and hospitals, ${ }^{15}$ where services tend to be disjointed. ${ }^{16}$ Without a primary care "quarterback" in charge, HNHC patients may experience avoidable and expensive downstream complications and costs. ${ }^{17}$

Spurred by the rise of value-based payment models, ${ }^{18}$ programs to redesign primary care for HNHC populations have recently proliferated. Though they vary in design, these programs attempt to empower primary care clinicians, supported by multidisciplinary teams, to reclaim the management of HNHC populations in an effort to achieve Starfield's aims. ${ }^{6}$ The rationale for investing in these efforts is that high-quality, 


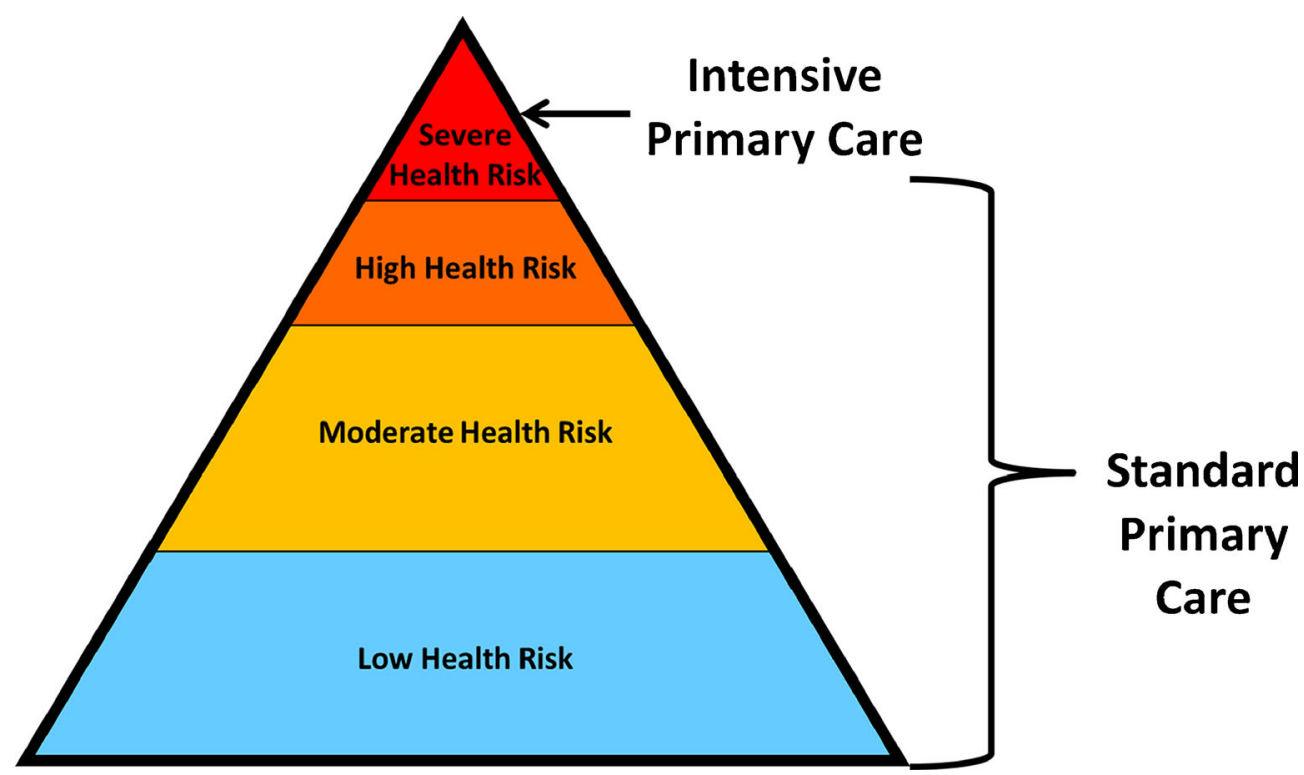

Figure 1 Stratification of health risk within a population. Patients with "severe health risk" represent the 5-20\% of the primary care population with the highest needs and costs. These are the patients most likely to benefit from intensive primary care services. Standard continuity primary care works best for those with moderate to high risk. The majority of the population, who are at low health risk, require only routine preventative care and episodic low acuity acute care.

patient-centric care will not only improve outcomes for HNHC patients, but will also yield dividends in the form of avoided downstream resource utilization. ${ }^{19,20}$

In this essay, we offer a clinical vignette highlighting the challenges of caring for $\mathrm{HNHC}$ populations. We then describe two primary care approaches for managing HNHC populations: complex case management ${ }^{21}$ and specialized clinics focused on HNHC patients. ${ }^{22}$ We conclude by suggesting policy reforms that could improve care for HNHC populations.

\section{CLINICAL VIGNETTE}

A 49-year-old man with a history of alcoholism, bipolar disorder, and an idiopathic cardiomyopathy has visited the emergency room seven times over the past year, resulting in three hospital admissions, all for the primary diagnosis of congestive heart failure. The patient recently received an implantable cardioverter defibrillator and a biventricular pacemaker. He lives with his brother in subsidized housing in a low-income part of the city where fast food restaurants are abundant and there are few supermarkets. He has Medicaid coverage, and is empanelled to a busy community primary care physician, whom he has seen irregularly for 2 years. He has "no-showed" for visits to this physician on two occasions over the past year. The primary care office staff left messages to reschedule his appointments but conducted no other outreach.

Because the patient has been flagged as a "hot-spotter" by his community hospital, a case manager has become involved in his case. The case manager has made another primary care appointment for him.
The patient arrives at his primary care doctor's office on a Friday afternoon, an hour-and-a-half late, because he missed the bus. Despite his tardiness and the fact that there are numerous other patients on the schedule, his primary care doctor agrees to see him. When the primary care doctor enters the room, she realizes that the faxed hospital records never arrived.

During the visit, the patient appears fatigued and anxious. He reports eating all his meals at McDonald's because "there's nowhere else to eat." He is uncertain about which medications he is taking, and forgot his pill bottles. He does report taking valproic acid, without which he "gets into trouble," as well as a "blood thinner." He can't recall the last time the level of the blood thinner was checked.

How should this primary care doctor manage her patient?

\section{APPROACH 1: COMPLEX CASE MANAGEMENT EMBEDDED WITHIN PRIMARY CARE}

Complex case management, also often called complex care management, refers to the provision of care coordination and support services for HNHC populations. ${ }^{23}$ These services may include everything from connecting patients with social service programs, to identifying and assisting with psychological or behavioral health needs, to providing protocol-driven disease management. The services may be provided by a wide array of providers, ${ }^{24}$ including social workers, nurses, medical assistants, and community health workers. These services may be superimposed on, or incorporated into, standard officebased primary care practices, as has been proposed in the patient-centered medical home model. ${ }^{25}$ 
Because it is generally not practical to hire dedicated case management staff in small community primary care practices, complex case management programs have predominately arisen within large, risk-bearing health systems that have a sufficient population to justify investment in dedicated staff. ${ }^{26}$ Examples include the complex case management programs offered by Kaiser, ${ }^{27}$ the U.S. Department of Veterans Affairs (VA), ${ }^{24}$ and Partners HealthCare. ${ }^{28}$

Complex case management may also be offered by entities serving multiple small primary care practices that, in aggregate, offer sufficient scale to justify the investment. Examples include the ubiquitous complex case management programs offered by third-party payers, ${ }^{29}$ the Community Care of North Carolina program offered by the state Medicaid agency, ${ }^{30}$ and the charitably funded Camden Coalition that serves HNHC individuals in Camden, $\mathrm{NJ}^{5}$

While in principle complex case management might seem an intuitive strategy for supporting HNHC populations, in practice the impact of these programs has been modest. ${ }^{10}$ Perhaps the most informative example to date was the Medicare Coordinated Care demonstration. In 2002, Medicare funded the demonstration to assess the value of intensive care coordination for chronically ill geriatric patients. ${ }^{31}$ The demonstration involved 15 organizations - commercial disease management companies, community hospitals, academic medical centers, an integrated delivery system, a hospice, a long-term care facility, and a retirement community. Most programs in the demonstration enrolled patients with chronic conditions who had been hospitalized within the previous year, and assigned them to a care coordinator (typically a registered nurse) who assessed them and developed a care plan. The coordinators, usually with caseloads $<100$, contacted patients several times per month, primarily by telephone.

Expectations for the program were high, ${ }^{32}$ but the results were disappointing. Relative to control patients, quality measures among enrollees improved only modestly; there was no reduction in hospitalization rates, and after discounting the upfront costs, none of the programs lowered overall expenditures. ${ }^{31}$

Still, some programs in the demonstration fared better than the rest. Most notably, Health Quality Partners, a non-profit disease management organization in Pennsylvania, reduced hospitalization rates and overall mortality among their enrollees, though the program did not lower total costs after discounting program fees. ${ }^{33}$ In contrast to other programs in the demonstration, care coordinators in the Health Quality Partners program provided regular in-person interaction with their assigned patients and had close relationships with their primary care clinicians. The coordinators also focused on coordinating care transitions and medication management. ${ }^{34}$ Other analyses of complex case management programs have similarly found that these strategies are essential for success. ${ }^{10}$

\section{APPROACH 2: DEDICATED PRIMARY CARE CLINICS FOR HIGH-NEEDS, HIGH-COST PATIENTS}

Another approach for managing HNHC patients involves the establishment of specialized primary clinics offering concentrated complex case management resources, including multidisciplinary personnel, all in one place. Primary care clinicians who work in these clinics typically have reduced panel sizes - sometimes less than $200^{35}$ vs. a standard primary care panel of $>2,000^{36}$ - to enable more individualized attention for enrolled patients.

One of the best known examples of such clinics was developed at The Boeing Company, a large self-insured employer. In 2007, Boeing established an intensive primary care clinic for the $15 \%$ of its employees with the highest health care costs. Patients enrolled in the clinic are supported by a primary care physician and a multidisciplinary team led by a nurse or social work coordinator with a panel of 150-200 patients. ${ }^{37}$ Upon enrollment, patients receive a health assessment to identify their medical and social needs, and develop a care plan in collaboration with their team. Because of enriched resources in the clinic, patients may interact with their care team at all hours, and can usually schedule visits on a next-day basis. A controlled, though not peer-reviewed, evaluation found that the Boeing program produced substantial improvements in patients' physical and mental functioning, a $56 \%$ reduction in missed work days, and a $20 \%$ reduction in the monthly cost of care, driven in part by a $55 \%$ reduction in emergency department visits. ${ }^{38}$

Another well-known primary care program for HNHC populations is Medicare's Program of All-Inclusive Care for the Elderly (PACE), which has over 100 sites nationwide. PACE targets older community-dwelling patients with medical and functional comorbidities meeting criteria for nursing home placement. ${ }^{39}$ PACE programs-which accept full financial risk for their populations - offer rich complex case management resources, and provide many non-traditional services, such as furnishing air conditioners during summer heat waves and arranging for social outings. They are also culturally tailored to their population. ${ }^{40}$ Primary care clinicians in PACE programs often have panel sizes of less than $200 .^{41}$ Compared to the general Medicare population, PACE enrollees experience lower emergency room, hospital, specialty care, and nursing home utilization, and lower overall mortality, ${ }^{39}$ though there has yet to be a rigorous prospective controlled evaluation of the program.

There have been a number of iterations of clinic models for HNHC patients. Some have done away with the brick-andmortar clinic entirely, instead bringing primary care services directly into the home environment. ${ }^{42-44}$ In other models, patients receive longitudinal primary care from their regular clinicians, but are referred to specialized clinics during highrisk periods, such as perioperatively or following a hospitalization. The Medicare Advantage group CareMore ${ }^{45}$ offers one such program, and a team at the University of Chicago is 
currently testing a similar model, the Comprehensive Care Physician Model. ${ }^{46}$

\section{DISCUSSION OF THE CLINICAL VIGNETTE}

The vignette described above highlights both the challenges and opportunities for managing $\mathrm{HNHC}$ patients in the primary care setting. The patient in the vignette suffers not just from complex medical comorbidities, but also from social and behavioral challenges that adversely impact his health. $\mathrm{He}$ would clearly benefit from intensive medical, social, and psychosocial services, specifically assistance planning for medical appointments, identifying healthful dietary options, managing his medications, and connecting with social and behavioral support services. No one is better positioned to oversee his care than his primary care clinician. Yet most primary care physicians lack the resources to coordinate these services, and as a result his care may end up fragmented.

Both of the primary care programs for HNHC patients described in this essay could benefit the patient in this vignette. One option would be for his existing primary care clinician to refer him to a specialized HNHC clinic, where he would be reassigned to a new primary care clinician with a smaller panel size and more time and resources to devote to his care. In such a clinic, other team members - such as social workers, behavioral health experts, and health educators - would be available to proactively support his care. Such clinics are in short supply, however, particularly in low-income communities, ${ }^{6}$ and it is far from certain he would have access to such a program, even in a Medicaid managed care environment.

As an alternative, this patient's existing primary care clinician might continue overseeing his care, with support from complex case management resources in the community, e.g. from the patient's health plan or a community organization. The highest-yield programs utilize coordinators who develop close relationships with patients and their primary care clinicians, and focus on care transitions and medication management (though many real-world organizations do not meet these specifications). Unfortunately, most Medicaid programs do not reimburse primary care clinicians for their efforts in coordinating this care (though recently Medicare began offering a modest care management fee to support such activities ${ }^{47}$ ).

\section{POLICY CHANGES TO IMPROVE CARE FOR HIGH- NEEDS, HIGH-COST PATIENTS}

As this vignette highlights, providing high-quality primary care for HNHC patients in a community setting often requires extraordinary effort. This underscores the need for policy changes to facilitate caring for HNHC populations.

Of the two approaches for managing HNHC populations described in this essay, existing evidence, though nascent, suggests that specialized clinics for HNHC populations offer more hope for substantially improving care of $\mathrm{HNHC}$ patients than complex case management embedded within, or superimposed upon, traditional primary care practices. Such specialized clinics for HNHC populations have begun to spread in recent years. ${ }^{48,49}$ Nevertheless, such clinics require substantial investment and a rethinking of the traditional primary care infrastructure, and thus remain few and far between. Likewise, complex case management programs have recently proliferated ${ }^{29}$; however, as many primary care clinicians and patients attest, ${ }^{13}$ these services vary in quality and can be difficult to access in a timely manner. ${ }^{50}$ Worst of all, resources for managing $\mathrm{HNHC}$ populations tend to be most scarce in low-income communities where medical and social complexity is most intense and where these services may be most needed. ${ }^{6}$

Nevertheless, we believe that modest policy changes could substantially increase the availability of primary care resources for HNHC populations. ${ }^{51}$

First, there is a need for changes in how care for HNHC populations is reimbursed. Traditional fee-for-service payment provides only limited reimbursement for the intensive services HNHC populations need, and programs that do cover these services like the Medicare care management fee ${ }^{47}$ are available in only a small number of situations. Even large health delivery systems that assume partial financial risk for their population may be hesitant to make large investments in HNHC populations because they reap only a fraction of the potential downstream savings from these investments. ${ }^{26}$ In contrast, organizations that assume full risk - such as the VA, Kaiser, CareMore, PACE, and some self-insured employers-tend to invest more heavily in their HNHC populations. ${ }^{29}$ Though full-risk models are impractical in many settings, a shift towards risk-bearing arrangements, as well as value-based reimbursement models ${ }^{18}$ and shared-savings programs like accountable care organizations, ${ }^{52}$ is likely to increase investment in HNHC populations. Moreover, reimbursement models should recognize not just traditional medical comorbidities but also social factors when adjusting for risk. $^{53}$

Another factor that may stymie efforts for improving care for HNHC populations is the fact that funding for medical, behavioral health, and social service delivery is often separate..$^{54,55}$ Particularly for HNHC individuals, social determinants such as housing, health literary, food security, and access to healthy food and exercise opportunities as well as behavioral health resources are likely to influence health outcomes to a greater extent than are medical services. ${ }^{56}$ As a result, even health systems that bear full financial risk for their population may be limited in the services they can offer HNHC patients. ${ }^{57}$ Better integration of medical, behavioral health, and social service delivery, such as the models currently being tested as part of state waivers for managing dualeligible populations, ${ }^{58}$ the Centers for Medicare \& Medicaid Services Accountable Health Communities demonstration, ${ }^{59}$ and the British "personal health budgets" program, ${ }^{60}$ could bolster the ability of health care delivery systems, and primary care clinicians in particular, to meet the needs of HNHC patients. ${ }^{61}$ 
A final challenge for improving care for HNHC populations is that, with a handful of exceptions (some of which were noted in this essay), there are few rigorous studies of HNHC programs. ${ }^{10}$ Part of the explanation for this is that evaluating programs for HNHC populations presents unique hurdles. Patients selected for extreme cost and utilization patterns tend to improve over time due to regression to the mean. ${ }^{62}$ Thus, to rigorously evaluate HNHC programs, it is critical to include well-matched contemporaneous control groups - which adds complexity and cost to the evaluation. Still, to provide health system leadership with data to justify investments in programs for HNHC patients, as well as to ensure that these programs are designed efficiently, it will be necessary to make these research investments. ${ }^{51}$

Fortunately, many of the reforms we have suggested are already under way. In some regions, health care delivery organizations are accepting more financial risk and accountability for their populations. ${ }^{30}$ As noted above, efforts are also starting to take shape, albeit slowly, to integrate the delivery of medical, behavioral health, and social services through state initiatives ${ }^{58}$ and national demonstrations. $^{59}$ Moreover, federal ${ }^{63}$ and foundation ${ }^{6}$ funders have prioritized investment in research for $\mathrm{HNHC}$ populations. The need to improve care for HNHC populations offers a compelling reason to maintain momentum for these policy changes.

\section{CONCLUSION}

As other articles in this symposium highlight, there is a pressing need for new strategies to reinvigorate primary care. HNHC populations are among those most likely to benefit from such reforms. Indeed, without better strategies for managing resource-intensive patients, these timeconsuming patients may stymie more general efforts to redesign primary care for the twenty-first century.

For HNHC populations, perhaps more than for any other group, the foundation of high-quality primary care rests on four simple attributes: being available for patients when needed, caring for them in a holistic manner, offering comprehensive services, and serving as the quarterback of their care. The challenge is how to provide primary care clinicians and their teams with the support and resources needed to deliver on these objectives for their most vulnerable patients.

Acknowledgments: This article was supported in part by a grant from the California Health Care Foundation to the Journal of General Internal Medicine (administered through UC Davis). The views expressed herein do not necessarily reflect those of the Foundation, JGIM, or SGIM.

Corresponding Author: Michael Hochman, MD, MPH; The Gehr Family Center for Implementation Science, Keck School of MedicineUniversity of Southern California, 2020 Zonal Ave., IRD 320, Los Angeles, CA 90033, USA (e-mail: mhochman@med.usc.edu).

\section{Compliance with Ethical Standards:}

Conflict of Interest: Dr. Hochman co-directs a clinician training program in partnership with CareMore, one of the health care delivery organizations highlighted in this article. There are no other conflicts of interest to report.

\section{REFERENCES}

1. Starfield B, Shi L, Macinko J. Contribution of primary care to health systems and health. Milbank Q. 2005;83(3):457-502.

2. Shrank WH. Primary care practice transformation and the rise of consumerism. J Gen Intern Med. [in press].

3. Kroenke $\mathbf{K}$, Unutzer $\mathbf{J}$. Closing the false divide: sustainable approaches to integrating mental health services into primary care. J Gen Intern Med. [in press].

4. Young HM, Nesbitt TS. Increasing the capacity of primary care through enabling technology. J Gen Intern Med. [in press].

5. Gawande A. The hot spotters. The New Yorker; 2011.

6. Blumenthal D, Chernof B, Fulmer T, Lumpkin J, Selberg J. Caring for High-Need, High-Cost Patients - An Urgent Priority. N Engl J Med. 2016;375(10):909-11.

7. Hochman M. Improvement happens_earning to better care for "superutilizers" at denver health: an interview with holly batel. improvement happens-learning to better care for "super-utilizers" at denver health: an interview with holly batel. J Gen Intern Med. 2016.

8. Stanton MW, Rutherford MK. The high concentration of U.S. health care expenditures. Rockville (MD): Agency for Healthcare Research and Quality; 2005. Research in Action Issue 19. AHRQ Pub. No. 06-0060.

9. McCarthy D, Ryan J, Klein S. Models of care for high-need, high-cost patients: an evidence synthesis. The Commonwealth Fund; 2015.

10. Hong C, Siegel A, Ferris T. Caring for high-need, high-cost patients: what makes for a successful care management program? The Commonwealth Fund; 2014.

11. Wang L, Porter B, Maynard C, Evans G, Bryson C, Sun H, Gupta I, Lowy E, McDonell M, Frisbee $\mathbf{K}$, Nielson C, Kirkland F, Fihn SD. Predicting risk of hospitalization or death among patients receiving primary care in the Veterans Health Administration. Med Care. 2013;51(4):368-73.

12. Lewis GH. Next steps for risk stratification in the NHS. January 2015. Available at: https://www.england.nhs.uk/wp-content/uploads/2015/ 01/nxt-steps-risk-strat-glewis.pdf

13. Schoen C, Osborn R, How SK, Doty MM, Peugh J. In chronic condition: experiences of patients with complex health care needs, in eight countries, 2008. Health Aff (Millwood). 2009;28(1):w1-16.

14. Schoen C, Osborn R, Doty MM, Squires D, Peugh J, Applebaum S. A survey of primary care physicians in eleven countries, 2009: perspectives on care, costs, and experiences. Health Aff (Millwood). 2009;28(6):w117183. doi: $10.1377 /$ hlthaff.28.6.w1171.

15. Lee NS, Whitman N, Vakharia N, Rothberg MB. High-cost patients: hotspotters don't explain the half of it. J Gen Intern Med. 2016.

16. Kanzaria HK, Hoffman JR. Hot-spotters aren't "the problem"...but they are emblematic of the failure of U.S. Healthcare. J Gen Intern Med. 2016.

17. Gibson OR, Segal L, McDermott RA. A systematic review of evidence on the association between hospitalisation for chronic disease related ambulatory care sensitive conditions and primary health care resourcing. BMC Health Serv Res. 2013;13:336.

18. Medicare Access and CHIP Reauthorization Act of 2015. Pub L No. 11410, 87 Stat 129 .

19. Porter ME. What is value in health care? N Engl J Med. 2010;363(26):2477-81. doi:10.1056/NEJMp1011024.

20. Friedmann PD, Hendrickson JC, Gerstein DR, Zhang Z, Stein MD. Do mechanisms that link addiction treatment patients to primary care influence subsequent utilization of emergency and hospital care? Med Care. 2006;44(1):8-15.

21. Pollack S, Hochman M. Improvement happens: team-based primary care, an interview with Stuart Pollack. J Gen Intern Med. 2015;30(4):521-8.

22. Lewis J, Hoyt A, Kakoza RM. Enhancing quality of primary care using an ambulatory ICU to achieve a patient- centered medical home. J Prim Care Community Health. 2011;2(4):234-9.

23. Kersbergen AL. Case management: A rich history of coordinating care to control costs. Nurs Outlook. 1996;44(4): 169-72.

24. Breland JY, Asch SM, Slightam C, Wong A, Zulman DM. Key ingredients for implementing intensive outpatient programs within 
patient-centered medical homes: A literature review and qualitative analysis. Healthc (Amst). 2016;4(1):22-9.

25. Zulman DM, Ezeji-Okoye SC, Shaw JG, Hummel DL, Holloway KS, Smither SF, Breland JY, Chardos JF, Kirsh S, Kahn JS, Asch SM. Partnered research in healthcare delivery redesign for high-need, highcost patients: development and feasibility of an Intensive Management Patient-Aligned Care Team (ImPACT). J Gen Intern Med. 2014;29(Suppl 4):861-9.

26. Kohn LT. Organizing and managing care in a changing health system. Health Serv Res. 2000;35(1 Pt 1):37-52.

27. Boult C, Karm L, Groves C. Improving chronic care: the "guided care" model. Perm J. 2008; 12(1):50-4.

28. McCall N, Cromwell J, Urato C. Evaluation of medicare care management for high cost beneficiaries (CMHCB) demonstration: Massachusetts General Hospital and Massachusetts General Physicians Organization (MGH). September 2010. Available at: http://www.massgeneral.org/ News/assets/pdf/FullFTIreport.pdf

29. Kongstvedt PR. Essentials of managed health care, Sixth Edition. Jones \& Bartlett Learning; 2012.

30. Steiner BD, Denham AC, Ashkin E, Newton WP, Wroth T, Dobson LA Jr. Community care of North Carolina: improving care through community health networks. Ann Fam Med. 2008;6(4):361-7.

31. Peikes D, Chen A, Schore J, Brown R. Effects of care coordination on hospitalization, quality of care, and health care expenditures among Medicare beneficiaries: 15 randomized trials. JAMA. 2009;301(6):603-18.

32. Brown R, Peikes D, Chen A, Schore J. 15-site randomized trial of coordinated care in Medicare FFS. Health Care Financ Rev. 2008;30(1):525.

33. Coburn KD, Marcantonio S, Lazansky R, Keller M, Davis N. Effect of a community-based nursing intervention on mortality in chronically ill older adults: a randomized controlled trial. PLoS Med. 2012;9(7):e1001265. doi:10.1371/journal.pmed.1001265.

34. Brown RS, Peikes D, Peterson G, Schore J, Razafindrakoto CM. Six features of Medicare coordinated care demonstration programs that cut hospital admissions of high-risk patients. Health Aff (Millwood). 2012;31(6):1156-66.

35. Peterson $\mathbf{K}$, Helfand $\mathbf{M}$, Humphrey $\mathbf{L}$, Christensen $\mathbf{V}$, Carson $\mathbf{S}$ Evidence brief: effectiveness of intensive primary care programs, VA-ESP Project \#09-199; 2013.

36. Altschuler J, Margolius D, Bodenheimer T, Grumbach K. Estimating a reasonable patient panel size for primary care physicians with team-based task delegation. Ann Fam Med. 2012;10(5):396-400. doi: $10.1370 /$ afm. 1400 .

37. Schilling B. Boeing's nurse case managers cut per capita costs by 20 percent. Purchasing High Performance. 2011.

38. Milstein A, Kothari PP. "Are higher-value care models replicable?" Health Affair Blog, 20 October, 2009, http://healthaffairs.org/blog/ 2009/10/20/are-higher-value-care-models-replicable/. Accessed 24 Oct. 2014.

39. Eng C, Pedulla J, Eleazer GP, McCann R, Fox N. Program of Allinclusive Care for the Elderly (PACE): an innovative model of integrated geriatric care and financing. J Am Geriatr Soc. 1997;45(2):223-32.

40. Kornblatt S, Eng C, Hansen JC. Cultural awareness in health and social services: The experience of On Lok. Generations. 2002;26(3):46.

41. Casillas E. Medical director for the AltaMed Program for all-inclusive care for the elderly, personal communication with author. 2015.

42. Counsell SR, Callahan CM, Clark DO, Tu W, Buttar AB, Stump TE, Ricketts GD. Geriatric care management for low-income seniors: a randomized controlled trial. JAMA. 2007;298(22):2623-33.
43. De Jonge KE, Jamshed N, Gilden D, Kubisiak J, Bruce SR, Taler G. Effects of home-based primary care on Medicare costs in high-risk elders. J Am Geriatr Soc. 2014;62(10):1825-31.

44. Buie S. "The A-ICU: health care, delivered to your home." The Atlantic, 15 Jan. 2014, http://www.theatlantic.com/sponsored/cvs-innovationcare/-icu-health-care-delivered-your-home/87/. Accessed 24 Oct 2016.

45. Reuben DB. Physicians in supporting roles in chronic disease care: the CareMore model. J Am Geriatr Soc. 2011;59(1):158-60.

46. Meltzer Do, Ruhnke GW. Redesigning care for patients at increased hospitalization risk: the Comprehensive Care Physician model. Health Aff (Millwood). 2014;33:770-7.

47. Aronson L, Bautista CA, Covinsky K. Medicare and care coordination: expanding the clinician's toolbox. JAMA. 2015;313(8):797-8.

48. Stremikis K, Hoo E, Stewart D. Using the intensive outpatient care program to lower costs and improve care for high-cost patients. Health Affairs Blog. 2016

49. Blash L, Chapman S, Dower C. The special care center- a joint venture to address chronic disease. Revised November 2011. Available at: http:// www.iorahealth.com/wp-content/uploads/2014/07/UCSF_The_Special_Care_Center_A_Joint_Venture_to_Address_Chronic_Disease.pdf.

50. Landon BE, Hicks LS, O'Malley AJ, Lieu TA, Keegan T, McNeil BJ, Guadagnoli E. Improving the management of chronic disease at community health centers. N Engl J Med. 2007;356(9):921-34.

51. Blumenthal D, Abrams MK. Tailoring complex care management for high-need, high-cost patients. JAMA. 2016.

52. Fisher ES, Staiger DO, Bynum JP, Gottlieb DJ. Creating accountable care organizations: the extended hospital medical staff. Health Aff (Millwood). 2007;26:w44-w57. doi:10.1377/hlthaff.26.1.w44.

53. Barnett ML, Hsu J, McWilliams JM. Patient characteristics and differences in hospital readmission rates. JAMA Intern Med. 2015; 175(11):1803-1812.

54. Escaron AL, Weir RC, Stanton P, Clarke RM. Defining and Rating the Effectiveness of Enabling Services Using a Multi-stakeholder Expert Panel Approach. J Health Care Poor Underserved. 2015;26(2):554-76.

55. Hochman M. Improvement happens: impacting health at its roots : an interview with Rishi Manchanda. Improvement happens: impacting health at its roots : an interview with Rishi Manchanda. 2014; 29(11):1552-6.

56. Schroeder SA. Shattuck Lecture. We can do better-improving the health of the American people. N Engl J Med. 2007;357(12):1221-8.

57. Davis $\mathbf{K}$, Buttorff $\mathbf{C}$, Leff $\mathbf{B}$, et al. Innovative care models for high-cost Medicare beneficiaries: delivery system and payment reform to accelerate adoption. Am J Manag Care. 2015;21(5):e349-e356.

58. Tobey R, Maxwell J, Bateman C, Barron C. Opportunities for wholeperson care in California [White paper]. 2014. Retrieved October 24 2016, from The California Department of Health Care Services: http:// www.dhcs.ca.gov/provgovpart/Documents/Waiver\%20Renewal/Workforce1_WPC2 JSI.pdf.

59. Fisher ES, Corrigan J. Accountable health communities: getting there from here. JAMA. 2014;312(20):2093-4.

60. O'Shea L, Bindman AB. Personal health budgets for patients with complex needs. N Engl J Med. 2016;375(19):1815-1817.

61. Taylor LA, Coyle CE, Ndumele C, et al. Leveraging the social determinants of health: what works? Available at: http:// bluecrossfoundation.org/sites/default/files/download/publication/Social_Equity_Report_Final.pdf. Accessed October 24, 2016.

62. Healy MJR, Goldstein H. Regression to the mean. 1978; 5(Iss. 3).

63. Clancy C, Collins FS. 2010. Sci Transl Med. 2010:2(37):37cm18. 